K.A. Brown MD, B. Bissonnette MD, H. Holtby MD, B. Shandling MB, S. Ein MD

\title{
Chest wall motion during halothane anaesthesia in infants and young children
}

Chest wall motion during anaesthesia may differ from the awake state because of the effect of anaesthetic agents on the muscles of respiration. The purpose of this study was twofold (I) to describe the pattern of chest wall motion in infants and children during halothane anaesthesia $(H A)$ using respiratory inductive plethysmography (RIP) and (2) to calibrate the voltage output of $R I P$ in units of volume. Seven infants $(2.3 \pm 1.7 \mathrm{mo}, 5.9 \pm 0.7$ $\mathrm{kg})$ and five children $(2.9 \pm 1.1 \mathrm{yr} .15 .5 \pm 1.5 \mathrm{~kg})$ were studied. Since results in both age groups were qualitatively similar they are presented as a single group. Respiratory excursions of the rib cage ( $R C)$ and abdomen $(A B D)$ were measured using RIP. Airflow was measured with a pneumotachograph. During spontaneous breathing the analogue signals of airflow, pressure, $R C$ and $A B D$ were recorded. Measurements were taken during (1) halothane anaesthesia and (2) during emergence from anaesthesia. The $X Y$ plots of the $R C$ and $A B D$ signals were plotted for each period. In addition the voltage output of the respiratory excursions of the $R C$ and $A B D$ signals was converted to units of volume using the simultaneous solution of equation method. The accuracy of conversion factors was validated by regression analysis of the predicted and measured tidal volume using breaths sampled at random throughout the entire period of study. Regression analysis of this relationship gave a slope between 0.85 and $1.15\left(r^{2}\right.$ value $\left.>0.7\right)$ in five of the twelve

\section{Key words}

ANAESTHESIA: paediatric;

ANAESTHETICS, VOLATILE: halothane;

MEASUREMENT TECHNIQUES: respiratory inductance

plethysmography;

VENTILATION: anaesthetics, effects of.

From the Departments of Anaesthesiology and Surgery and the Research Institute, The Hospital for Sick Children, University of Toronto, Ontario, Canada, M5G 1 X8.

Address correspondence to: Dr. K.A. Brown, The Montreal Children's Hospital, 2300 Tupper St., Montreal, Quebec H3H IP3.

Accepted for publication 12th August, 1991. patients. The pattern of chest wall motion in the $X Y$ plots showed synchronous motion between $R C$ and $A B D$ signals during $H A$ in nine of the nvelve patients. Three patients showed paradoxical inward motion of the $R C$ during inspiration. This finding differs from that of previous studies which showed asynchrony between the $R C$ and $A B D$ signals during $H A$.

La mobilité de la cage thoracique sous anesthésie peut différer de celle en état d'éveil à cause des effets des agents anesthésiques sur les muscles de la respiration. Cetle étude visait deux buts: I) décrire le type de mouvements de la cage thoracique chez les bébés et les enfants sous anesthésie à l'halothane (HA) en utilisant la pléthysmographie respiratoire par induction (RIP) et 2) calibrer le voltage de sortie de la RIP en unités de volume. Sept bébés $(2,3 \pm 1,7$ mois, $5,9 \pm 0,7 \mathrm{~kg})$ et cinq enfants $(2,9 \pm$ 1,1 ans, $15,5 \pm 1,5 \mathrm{~kg}$ ) ont été étudiés. Etant donné que les résultats dans les deux groupes étaient qualitativement semblables, ils ont été présentés comme provenant d'un groupe unique. Les déplacements respiratoires de la cage thoracique (RC) et de l'abdomen ( $A B D$ ) ont été mesurés en utilisant la RIP. Le débit d'air était mesuré à l'aide d'un pneumotachographe. Durant la respiration spontanée, les signaux analogues du débit d'air, de la pression, du RC et du ABD étaient enregistrés. Les mesures étaient prises () sous anesthésie à l'halothane et 2) durant l'émergence de l'anesthésie. Les graphiques $X Y$ des signaux $R C$ et $A B D$ étaient faits pour chaque période. De plus, le voltage de sortie des déplacements respiratoires à des signaux $R C$ et $A B D$ était converti en unités de volume en utilisant les méthodes de "solution simultanée de l'équation». La précision des facteurs de conversion était validée à l'aide d'une analyse de régression des volumes courants prédits et mesurés provenant de respirations au hasard tout au long de la période d'étude. $L$ 'analyse de régression de cente relation a donné une pente entre 0,85 et 1,15 (valeur de $r^{2}>0,7$ ) chez 5 des 12 patients. Le type de mouvements de la cage thoracique par le graphique $X Y$ a démontré des mouvements synchrones entre les signaux $R C$ et $A B D$ durant $H A$ chez 9 des 12 patients. Trois patients ont démontré un mouvement paradoxal du $R C$ vers l'intérieur durant l'inspiration. Cette trouvaille differe de celles d'études précédentes qui démontraient un asynchronisme entre les signaux $R C$ et $A B D$ durant $H A$. 
Anaesthesia may affect chest wall motion. In adults and older children chest wall motion during halothane anaesthesia (HA) is characterized by (1) a dose-related depression in the ribcage $(\mathrm{RC})$ contribution to tidal breathing and (2) thoraco-abdominal asynchrony. ${ }^{1-5}$ In fact, frank paradoxical inward motion of the rib cage with inspiration during HA has been documented. The chest wall motion during HA in infants and young children may differ from that observed in adults because anatomical and mechanical factors in the infant and young child result in a compliant chest wall. Therefore one might expect that chest wall motion during $\mathrm{HA}$ in infants would be characterized by paradoxical movement of the RC during respiration. The purpose of this study was to describe the pattern of chest wall motion during $\mathrm{HA}$ in infants and young children using respiratory inductive plethysmography.

Respiratory inductive plethysmography (RIP) has been used to partition tidal volume into rib cage and abdominal contributions. This requires that the voltage output of the ribcage (RC) and abdominal (ABD) signals be converted to units of volume. The calibration procedure of RIP in units of volume originally described by Konno and Mead involved an isovolume manoeuvre at different lung volumes. ${ }^{6}$ Calibration procedures in patients, such as infants, who are unable to perform an isovolume manoeuvre have been difficult and therefore alternative techniques for calibration of RIP have been developed which use the different patterns of chest wall motion during tidal volume breathing. In infants, differences in chest wall motion which occur during REM and non-REM sleep have been used. $^{7-12}$ We postulated that the variation in breathing pattern during HA could be used to calibrate the respitrace ${ }^{20}$.

\section{Methods}

The protocol was approved by the Institutional Ethics Committee on Human Experimentation. Written informed parental consent was obtained. Healthy fasted children undergoing elective inguinal herniorrhaphy were studed.

Anaesthesia was induced with either thiopentone, 5 $\mathrm{mg} \cdot \mathrm{kg}^{-1} i v$ or halothane, after atropine, $0.2 \mathrm{mg} \cdot \mathrm{kg}^{-1} i v$. The tracheas were not intubated, in fact endotracheal intubation was an exclusion criteria. An oropharyngeal airway was placed in all patients. Infants and children were anaesthetized using a modified Jackson Rees circuit with a fresh gas flow of $12 \mathrm{~L} \cdot \mathrm{min}^{-1}$. Resistance of the apparatus resulted in $1 \mathrm{~cm} \mathrm{H} \mathrm{H}_{2} \mathrm{O}$ at a $12 \mathrm{~L} \cdot \mathrm{min}^{-1}$ flow. Anaesthesia was maintained with $70 \% \mathrm{~N}_{2} \mathrm{O}$ in oxygen and an inspired halothane concentration of $2 \%$ in infants and $2.5 \%$ in children. All patients breathed spontaneously during the surgical procedure. Halothane and $\mathrm{N}_{2} \mathrm{O}$ were discontinued during closure of the surgical incision. The patients were allowed to emerge from anaesthesia without stimulation until spontaneous movement occurred, which indicated the end of the study.

Respiratory measurements included mask pressure, airflow and RIP. Mask pressure (Microswitch \#142PC050 Toronto, Canada) and flow (Fleisch pneumotachograph, \#0 in infants or \#1 in children, Microswitch \#163PC1D36 Toronto, Canada) were measured. Excursions of RC and ABD were measured with RIP (Respitrace ${ }^{\circledR}$, Ambulatory Monitoring, Inc. Ardsley, New York). Respitrace ${ }^{\circledR 3}$ bands of an appropriate size for the infant or child were used. The RC bands were centred at the nipple level. The ABD bands were placed with the inferior margin at the level of the umbilicus. The bands were not moved during the period of study.

Flow through both pneumotachographs was calibrated with the two gas mixtures used during the procedure (1) $70 \% \mathrm{~N}_{2} \mathrm{O}$ in oxygen and (2) $100 \%$ oxygen and the calibration was linear over the experimental range. The flow calibration was checked against a known volume at the beginning and at the end of each study. The coefficient of variation for repeated volume measures was $2.0 \%$.

In order to rule out a phase lag between RC and ABD signals the respitrace bands were wrapped around a balloon which was inflated at frequencies which ranged from $40-70 \mathrm{bpm}$. (These frequencies spanned the range of respiratory rates observed during spontaneous breathing and HA.) There was no phase lag between the RC and ABD signals over this range of frequency.

Sections of representative data were measured during halothane anaesthesia and emergence representing the stages of anaesthesia and sedation. Since emergence spanned a period of ten minutes, emergence was represented by data from the minute preceding spontaneous movement, which marked the end of the study.

The signals were recorded on a Hewlett Packard fourchannel magnetic tape recorder for off-line playback through a 12 bit analogue to digital conversion board (Data Translation DT2801-A, Transduction, Mississauga, Ont.), sampled at $50 \mathrm{~Hz}$ and recorded, as 30-sec data files, on a personal computer for off-line analysis (Anadat ${ }^{\circ}$, RHTInfoDat, Montreal, Canada). The flow signal was zero offset, drift corrected and numerically integrated to volume (VOL). The periods of inspiration ( $\mathrm{Ti}$ ) and expiration (Te) were defined from the flow signal by the points of zero flow crossing. All four signals underwent a breath-by-breath analysis. Breaths which showed evidence of a poor mask fit were identified from the pressure and flow signals and excluded from data analysis.

The $X Y$ plots of the $R C$ and $A B D$ signals were made (RC/ABD loops). The RC/ABD loops during HA were made by taking a 30-sec data file, containing 20-30 breaths and breath-averaging the $\mathrm{RC}, \mathrm{ABD}$ and $\mathrm{VOL}$ signals into a single representative signal $R C_{x}, A B D_{x}$ and 
$\mathrm{VPN}_{\mathrm{x}}$, respectively where the subscript $\mathrm{X}$ identifies $\mathrm{HA}(\mathrm{A})$ or Emergence (C). The computer algorithm made the breaths of equal duration by adding or removing points from the middle of the end expiratory pause. Breaths originally of duration $>30 \%$ different from the mean duration were excluded from the averaged signal.

The degree of synchrony between the RC and ABD signals in each $\mathrm{RC} / \mathrm{ABD}$ loop was quantitated by using the angle of phase shift $\theta$, a variable which was introduced by Agostoni and Allen. ${ }^{13.14}$ The angle of phase shift $\theta$ was calculated such that $\sin \theta=\mathrm{m} / \mathrm{s}$; where $\mathrm{s}=$ maximal $\mathrm{ABD}$ excursion during inspiration and $m=$ width of respitrace loop at mid-RC excursion. (For phase angle $>90^{\circ} \theta=$ $180^{\circ}-v$ where $\sin v=\mathrm{m} / \mathrm{s}$.)

The respitrace was calibrated in units of volume with a two-point calibration procedure using the RC/ABD loops from anaesthesia and emergence. Inspiratory excursions of $\mathrm{RC}_{\mathrm{x}}\left(\triangle \mathrm{RC}_{\mathrm{x}}\right)$ and $\mathrm{ABD}_{\mathrm{x}}\left(\triangle \mathrm{ABD}_{\mathrm{x}}\right)$ in volts and the corresponding tidal volume $\left(\mathrm{VPN}_{\mathrm{x}}\right)$ were obtained and solved using the simultaneous solution of equations method:

$$
\begin{aligned}
& \mathrm{VPN}_{\mathrm{A}}=\mathrm{a} \cdot \Delta \mathrm{RC}_{\mathrm{A}}+\mathrm{b} \cdot \Delta \mathrm{ABD}_{\mathrm{A}} \\
& \mathrm{VPN}_{\mathrm{C}}=\mathrm{a} \cdot \Delta \mathrm{RC} \mathrm{C}_{\mathrm{C}}+\mathrm{b} \cdot \Delta \mathrm{ABD}_{\mathrm{C}}
\end{aligned}
$$

where the subscripts $A$ and $C$ refer to anaesthesia and emergence respectively. ${ }^{8.10}$

The accuracy of the conversion factors $a$ and $b$ to predict tidal volume was validated by randomly sampling breaths throughout the surgical procedure. The conversion constants a and b were applied to the values of $\triangle R C$ and $\triangle A B D$ to obtain a predicted tidal volume (VPRED). The relationship between VPRED and the corresponding pneumotachographic volume (VPN) was described using linear regression to derive a slope and a coefficient of determination.

The respitrace was considered to be calibrated if previously published criteria were met, namely that the regression analysis of the VPN:VPRED relationship had: (1) a slope between 0.85 and 1.15 and (2) a correlation coefficient ( $r)$ greater than $0.85\left(r^{2}>0.72\right)$.

\section{Results}

Seven infants $(2.3 \pm 1.7 \mathrm{mo}, 5.9 \pm 0.7 \mathrm{~kg})$ and five children $(2.9 \pm 1.1 \mathrm{yr}, 15.5 \pm 1.5 \mathrm{~kg})$ were studied. No patient moved during surgical incision. There was no qualitative difference in chest wall motion during $\mathrm{HA}$ in infants and children and therefore the results are presented as a single group. There were no signs suggestive of upper airway obstruction. (The ratio of inspiratory time to the total breath duration (Ti/TTot) was $0.335 \pm 0.035$ where TTot is the total duration of the breath.) Tidal volume for the group ranged from $3.2 \pm 0.7 \mathrm{ml} \cdot \mathrm{kg}^{-1}$ during $\mathrm{HA}$ to $6.8 \pm 1.4 \mathrm{ml} \cdot \mathrm{kg}^{-1}$ during emergence.

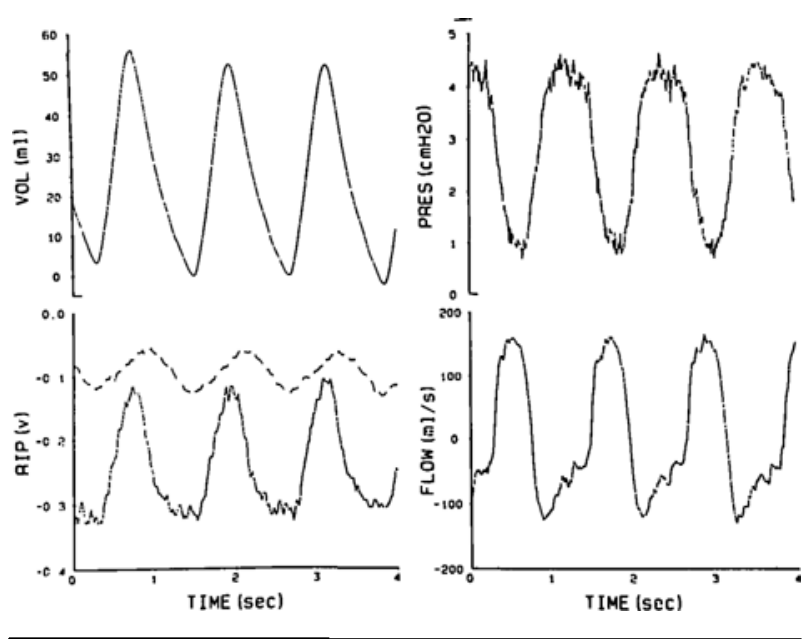

FIGURE 1 Shows four scconds of representative data during HA from palient \#4 where the VOL is the numerically integrated flow signal, PRES is the pressure within the mask. By convention inspiratory flow is positive and expiratory flow is negative. The resistive properties of the anaesthetic circuit resulted in $2-4 \mathrm{~cm} \mathrm{H}_{2} \mathrm{O}$ positive pressure during the respiratory cycle. The panel labelled RIP contains both the ABD signal (-) and the RC signal (---). The ABD signal is synchronous with the VOL signal. The peak of the RC signal occurs later than the peak in the ABD signal. This lag in the RC signal relative to inspiration was observed in most patients and resulted in an opening of the RC/ABD loop at end expiration (Figure 2). During HA the end-inspiratory lag in the $\mathrm{RC}$ signal relative to the $\mathrm{ABD}$ signal was $0.12 \pm 0.10 \mathrm{sec}$.

In all patients inspiratory and expiratory excursions of the ABD trace were synchronous with the inspiratory and expiratory phases in the flow signal. In contrast the peak in the inspiratory excursion of the $\mathrm{RC}$ trace lagged behind the peak of the ABD trace. During anaesthesia the peak of the $\mathrm{RC}$ trace occurred about $0.12 \pm 0.10(\overline{\mathrm{x}} \pm \mathrm{SD}) \mathrm{sec}$ after the peak in the abdominal trace (Figure 1).

The RC/ABD loops in Figure 2, Panel A show fairly synchronous movement of the $\mathrm{RC}$ and $\mathrm{ABD}$ trace. The phase angle $\theta$ during $\mathrm{HA}$ was $<60^{\circ}$ for most patients (Table I). However, not all patients showed synchronous $\mathrm{RC}$ and $\mathrm{ABD}$ interaction. Panel $\mathrm{B}$ shows three patients for whom $\theta>60^{\circ}$ during $\mathrm{HA}$ due to paradoxical inward movement of RC during inspiration. In fact the patient to the far right shows complete paradoxical inward motion of the $\mathrm{RC}$ during inspiration.

The calibration technique used for RIP for a representative patient is shown in Figure 3. The RC/ABD loops during $\mathrm{HA}$ and emergence were used to derive the inspiratory excursions of $R C(\triangle R C)$ and $A B D(\triangle A B D)$ in volts where $A$ is during $H A$ and $C$ is during emergence. Note that the size of the RC/ABD loop obtained during HA was smaller than that during emergence. The tidal volume (VPN) was also smaller such that $\mathrm{VPN}_{\mathrm{A}}=2.4 \mathrm{ml} \cdot \mathrm{kg}^{-1}$ 

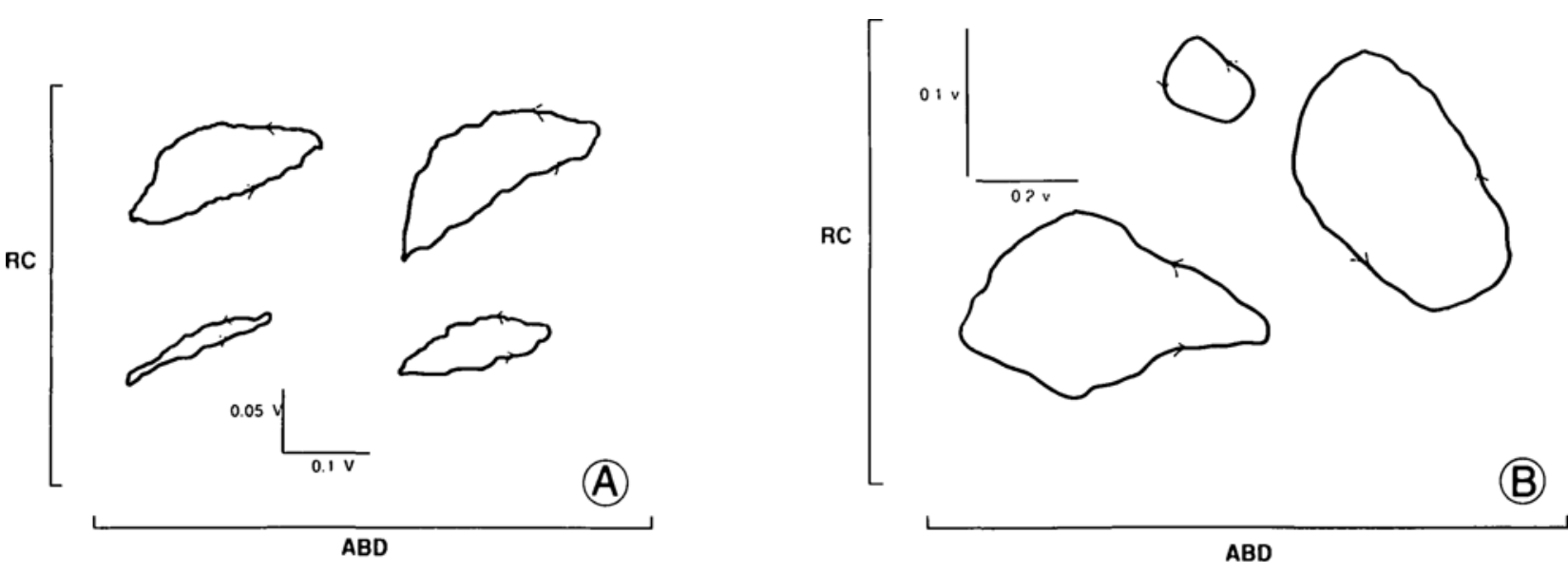

FIGURE 2 Two panels showing individual RC/ABD loops during HA. Note the difference in scales on the $X$ and $Y$ axis. The voltage excursion of the ABD signal is greater than that of the RC signal. From Figure $l$ it is evident that the positive excursion ABD signal was synchronous with inspiration (RC and ABD signals increased simultaneously). This was true for all patients. Therefore, for the RC/ABD loops inspiration corresponds to the positive excursion of the ABD signal. Panel A shows loops with synchronous RC and ABD intcraction. Pancl B shows loops with asynchronous $\mathrm{RC}$ and $\mathrm{ABD}$ movement and complete paradoxical motion of RC in two loops.

TABLE I Values for $\theta$ for RC/ABD loops obtained during HA and emergence (EM). In the majority of patients $\theta<60^{\circ}$ indicating a fairly synchronous pattern of RC and $\mathrm{ABD}$ interaction

\begin{tabular}{lll}
\hline & $\theta$ & \\
\cline { 2 - 3 } Patient & $H A$ & $E M$ \\
\hline$\# 1$ & $11^{\circ}$ & $6^{\circ}$ \\
$\# 2$ & $90^{\circ}$ & $14^{\circ}$ \\
$\# 3$ & $5^{\circ}$ & $60^{\circ}$ \\
$\# 4$ & $48^{\circ}$ & $58^{\circ}$ \\
$\# 5$ & $32^{\circ}$ & $46^{\circ}$ \\
$\# 6$ & $10^{\circ}$ & $33^{\circ}$ \\
$\# 7$ & $17^{\circ}$ & $13^{\circ}$ \\
$\# 8$ & $11^{\circ}$ & $15^{\circ}$ \\
$\# 9$ & $71^{\circ}$ & $57^{\circ}$ \\
$\# 10$ & $21^{\circ}$ & $64^{\circ}$ \\
$\# 11$ & $10^{\circ}$ & $28^{\circ}$ \\
$\# 12$ & $90^{\circ}$ & $156^{\circ}$ \\
$\bar{X} \pm$ SD & $34.7^{\circ} \pm 32.1$ & $45.83^{\circ} \pm 40.51$ \\
\hline
\end{tabular}

and $V P N_{C}=10.0 \mathrm{ml} \cdot \mathrm{kg}^{-1}$. The equations $\mathrm{VPN}_{\mathrm{A}}=$ $\mathrm{a} \cdot \Delta \mathrm{RC}_{\mathrm{A}}+\mathrm{b} \cdot \Delta \mathrm{ABD}_{\mathrm{A}}$ and $\mathrm{VPN}_{\mathrm{C}}=\mathrm{a} \cdot \Delta \mathrm{RC}_{\mathrm{C}}+\mathrm{b} \cdot \Delta \mathrm{A}-$ $B D_{C}$ (where the subscripts $A$ and $C$ refer to $H A$ and emergence, respectively) were solved by the simultaneous solution of equations method for the conversion factors a and $b$.

Figure 4 shows the relationship between VPRED and VPN for the patient in Figure 3. Linear regression of this relationship gave the equation: $\mathrm{RC}=1.1 \mathrm{ABD}-0.08\left(\mathrm{r}^{2}\right.$ $=0.94)$. The results of the linear regression for the VPRED and VPN relationship for the other children are given in Table II. Five out of 12 patients met the calibration criteria. An additional three patients had an $r^{2}$ value
TABLE II Demographic data and regression analysis of the VPRED vs VPN relationship for all patients

\begin{tabular}{|c|c|c|c|c|}
\hline \multirow[b]{2}{*}{ Patient } & \multirow[b]{2}{*}{$W t(k g)$} & \multirow[b]{2}{*}{ Age(mo) } & \multicolumn{2}{|c|}{$\begin{array}{l}\text { Regression analysis } \\
\text { VPRED vs VPN }\end{array}$} \\
\hline & & & Slope & $r^{2}$ \\
\hline$\# 1$ & 6.6 & 3 & 1.07 & 0.94 \\
\hline$\# 2$ & 6.0 & 2 & 1.09 & 0.85 \\
\hline$\# 3$ & 14.0 & 42 & 1.03 & 0.88 \\
\hline$\# 4$ & 18.0 & 54 & 1.12 & 0.93 \\
\hline$\# 5$ & 16.0 & 30 & 0.84 & 0.90 \\
\hline \#6 & 16.0 & 24 & 1.24 & 0.90 \\
\hline$\# 7$ & 5.9 & 3 & 0.89 & 0.89 \\
\hline$\# 8$ & 6.0 & 3 & 1.39 & 0.78 \\
\hline \#9 & 15.0 & 24 & 1.14 & 0.70 \\
\hline$\# 10$ & 5.2 & 3 & 0.67 & 0.58 \\
\hline$\# 11$ & 5.8 & 3 & 1.18 & 0.44 \\
\hline$\# 12$ & 5.0 & 2 & -38.2 & 0.02 \\
\hline
\end{tabular}

$>0.72$. However, values for the slopes of the regression analysis in these three patients were not within $15 \%$ of the line of identity.

\section{Discussion}

The inspiratory excursions of both $\mathrm{RC}$ and $\mathrm{ABD}$ traces were less during $\mathrm{HA}$ than during emergence and this is consistent with the notion that HA decreases the amplitude of the phasic EMG activity in both the intercostal and diaphragmatic muscles. ${ }^{1,4}$

We expected to see paradoxical movement of RC with inspiration because this is the pattern seen in adults during HA. ${ }^{1-4}$ Furthermore, it was anticipated that the child's 


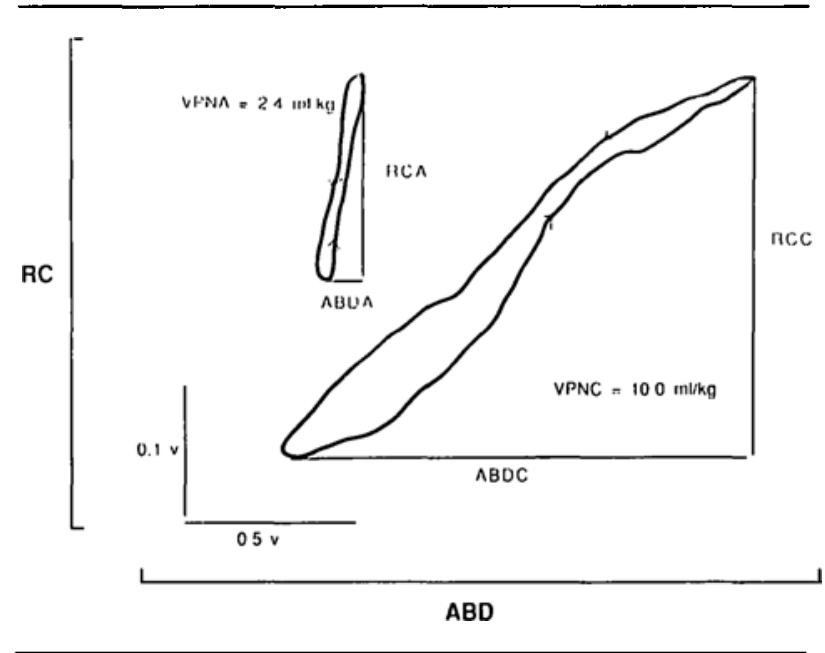

FIGURE 3 This figure shows the method of respitrace ${ }^{\text {st: }}$ calibration in a representative patient. The RC/ABD loops for HA and emergence were used to derive the inspiralory excursions of $R C(\triangle R C)$ and $A B D$ $(\triangle A B D)$ in volts. The size of the RC/ABD loop obtained during HA was smaller than that during emergence. The tidal volume (VPN) was also smaller such that $V P N_{A}=2.4 \mathrm{ml} \cdot \mathrm{kg}^{-1}$ and $V P N_{C}=10.0$ $\mathrm{ml} \cdot \mathrm{kg}^{-1}$. The equations $\mathrm{VPN}_{\mathrm{A}}=\mathrm{a} \cdot \Delta R \mathrm{C}_{\mathrm{A}}+\mathrm{b} \cdot \triangle \mathrm{ABD}_{\mathrm{A}}$ and $\mathrm{VPN}_{\mathrm{C}}$ $=\mathrm{a} \cdot \Delta \mathrm{RC}_{\mathrm{C}}+\mathrm{b} \cdot \Delta \mathrm{ABD}_{\mathrm{C}}$ (where the subscripts $\mathrm{A}$ and $\mathrm{C}$ refer to $\mathrm{HA}$ and emergence, respectively) were solved by the simultaneous solution of equations method for the conversion factors $a$ and $b$.

immature thoracic cage, and the halothane-induced decrease in intercostal muscle tone, would result in a very compliant chest wall during $\mathrm{HA}$. However, the $\mathrm{XY}$ plots of the RC/ABD loops during HA showed synchronous movement of the $R C$ and $A B D$ traces and for the majority of patients, a phase angle $\theta<60^{\circ}$ during HA.

This finding was unexpected but may be explained if the pressure gradient acting across the chest wall during HA is considered. During HA respiratory efforts were decreased. Therefore, the pressure gradient acting across the ribcage during inspiration would be less than in the awake state. In addition, as shown in Figure I, the resistive properties of the anaesthetic circuit resulted a CPAP of $2-5 \mathrm{~cm} \mathrm{H}_{2} \mathrm{O}$ which might act as a pressure splint to minimize inward motion of $\mathrm{RC}$ during inspiration.

Previous studies showing paradoxical inspiratory motion of RC during HA differed in two important aspects, from our study. Firstly, all involved tracheal intubation, probably with endotracheal tubes (ETT) ranging in size from 4-6.5 mm internal diameter. The ETT represents a resistor. ${ }^{15}$ It is known that air flow obstruction of both the upper and lower airway is associated with asynchronous $\mathrm{RC}$ and $\mathrm{ABD}$ movement. ${ }^{13}$

Secondly, previous studies used lower concentrations of halothane and respiratory efforts may have been greater than we observed. These two factors, respiratory effort and the presence of a resistor during inspiration, would contribute to asynchrony between the RC and ABD traces.

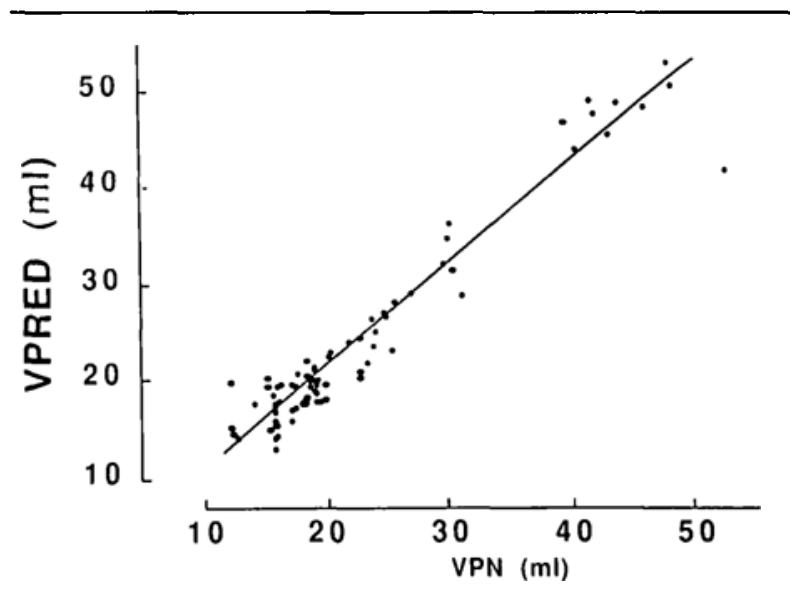

FIGURE 4 This figure plots VPN (abscissa) and VPRED (ordinate) for the patient in Figure 3 in order to validate the accuracy of the conversion faciors $a$ and $b$. VPRED was obtained by applying the conversion factors a and $b$ to values of $\triangle R C$ and $\triangle A B D$ recorded throughout the surgical procedure. Linear regression analysis of the relationship gave the equation VPRED $=1.1$ VPN $-0.08\left(r^{2}=0.94\right)$.

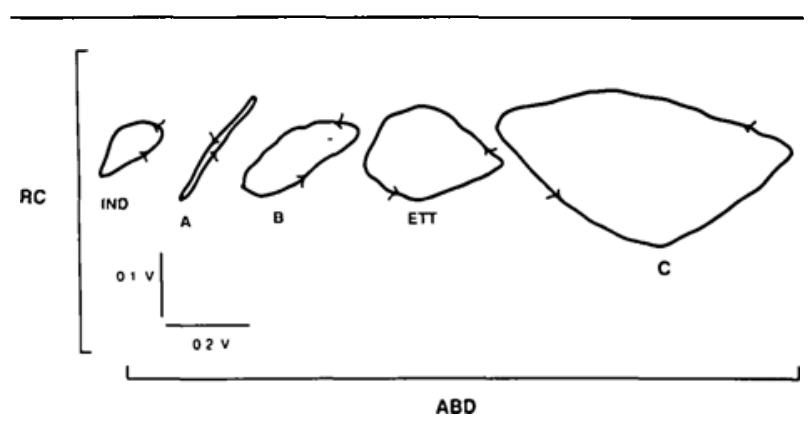

FIGURE 5 This figure shows the changes in the shape of the RC/ABD loops for a 7 -month, $7 \mathrm{~kg}$ infant who required tracheal intubation during the procedure. The RC/ABD loops are identified as follows: IND (induction of HA), A (HA before skin incision), B (HA during ligation of the hemia sac), ETT (post-intubation) and C (emergence from anaesthesia). During emergence the trachea remained intubated. There was synchronous RC and ABD motion during IND, $A$ and $B$. Following tracheal intubation (ETT) asynchronous motion of the RC and ABD traces was observed and persisted during emergence.

Figure 5 shows the RC/ABD loops from a seven-month $(7 \mathrm{~kg})$ infant who required tracheal intubation for laryngospasm and supports the notion that the presence of asynchronous $\mathrm{RC}$ and $\mathrm{ABD}$ motion during $\mathrm{HA}$ is influenced by intubation and respiratory effort. Intubation of the trachea was achieved with a $3.5 \mathrm{~mm}$ id, $11 \mathrm{~cm}$ ETT. (Muscle relaxants were not used to facilitate intubation.) The $\mathrm{RC} / \mathrm{ABD}$ loops for different periods in the surgical procedure are shown, where IND is during induction, $A$ is during HA prior to surgical incision, $B$ is during $H A$ and ligation of the hernia sac, ETT is after tracheal intubation and $\mathrm{C}$ is during emergence. Intubation resulted in paradox- 
ical inward motion of RC during inspiration and outward motion during expiration. The presence of an ETT and the increased respiratory effort associated with emergence from anaesthesia were associated with paradoxical inward motion of RC during inspiration.

The calibration criteria were met in five of the twelve children studied which compares with a previous study applying similar methods to premature infants. ${ }^{11}$ However, the fact that in seven children the calibration criteria were not met limits the use of the simultaneous solution of equations method as a method of calibration of RIP in units of volume. The fact that for all but patient \#12 the slope of the linear regression of the VPN:VPRED was linear and positive showed that qualitatively the sum of the $\triangle R C$ and $\triangle A B D$ signals followed the changes in tidal volume. However, as a quantitative and accurate noninvasive measurement of tidal volume calibration of RIP with the simultaneous solution of equation methods was not satisfactory.

Calibration techniques for RIP using the variation in the pattern of chest wall motion during tidal breathing make several assumptions. One of these states that the chest wall behaves with two degrees of freedom. ${ }^{6}$ During anaesthesia the patients did not move and therefore it is reasonable to assume that the spinal angle was fixed and that this assumption was met. However, techniques using the different patterns of chest wall motion during tidal breathing assume that these patterns of breathing are different. During HA and emergence, the pattern of breathing was predominantly diaphragmatic and may not have been sufficiently different to derive accurate conversion factors. In addition, examination of the RC/ABD loops in Figure 2 shows a complex interaction between $R C$ and $A B D$ traces and suggests that the two-point calibration procedure inherent to the simultaneous solution of equations method may oversimplify the interaction between the RC and $\mathrm{ABD}$ compartments.

In conclusion the pattern of chest wall motion during surgical planes of HA observed in this study showed predominantly diaphragmatic breathing and this is in agreement with previous studies. The RC/ABD loops show that, in the presence of an unobstructed airway, synchronous motion between RC and ABD traces may occur even at a deep plane of HA. This suggests that deep HA is not always associated with paradoxical inward motion of the RC during inspiration. In addition we found that a two-point calibration using the simultaneous solution of equations method satisfied the calibration criteria in only five out of twelve patients, which limits its application as an alternate to pneumotachography in the measurement of respiratory volumes.

\section{Acknowledgements}

Supported by PSI Foundation. We would like to thank Drs.
B. Brummitt, L. Gerus and B. Macpherson for their cooperation and Dr. A.C. Bryan for his encouragement and advice. We also appreciate the expertise of Mrs. R. Cacolyris and Ms. J. Warda in preparing the manuscript.

\section{References}

I Tusiewicz K, Bryan AC, Froese AB. Contributions of changing ribcagc-diaphragm interactions to the ventilatory depression of halothane anaesthesia. Anesthesiology 1977; 27: 327-37.

2 Lindahl SGE, Yates AP, Hatch DJ. Respiratory depression in children at different end tidal halothane concentrations. Anaesthesia 1987; 42: 1267-75.

3 Jones JG, Faithfull D, Jordan $C$ et al. Rib cage movement during halothane anaesthesia in man. $\mathrm{Br} \mathrm{J}$ Anaesth 1979; 51: 399-406.

4 Rehder K, Marsh HM. Respiratory mechanics during anacsthesia and mechanical ventilation. In: Fishman AP, Macklem PT, Meed J, Geiger SR (Eds.). The Handbook of Physiology, Section 3, The Respiratory System. Vol III Part 2. Baltimore: Waverly Press Inc., 1986: 737-52.

5 Bryan AC, Wohl ME. Respiratory mechanics in children. In: Fishman AP, Macklem PT, Meed J, Geiger SR (Eds.). The Handbook of Physiology, Section 3, The Respiratory System. Vol III Part I. Baltimore; Waverly Press Inc., 1986: 179-91.

6 Konno K, Mead J. Measurement of the scparate volume changes of rib cage and abdomen during breathing. J Appl Physiol 1967; 22: 407-22.

7 Henderson-Smart DJ, Read DJ. Reduced lung volume during behavioral active sleep in the newborn. J Appl Physiol 1979; 46: 1081-5.

8 Chadha TS, Watson H, Birch S et al. Validation of respiratory inductive plethysmography using different calibration procedures. Am Rev Respir Dis 1982; 125: 644-9.

9 Duffy $P$, Sprut L, Bryan $M H$, Bryan AC. Respiratory induction plethysmography (Respitrace ${ }^{9}$ ): an evaluation of its use in the infant. Am Rev Respir Dis 1981; 123: 542-6.

10 Warren RH, Alderson S. Calibration of computer-asserted (respicomp) respiratory inductive plethysmography in newborns. Am Rev Respir Dis 1985; 131: 564-7.

11 Wilkes $D L$, Revow M, Bryan MH, England SJ. Evaluation of respiratory inductive plethysmography in infants weighing less than 1500 grams. Am Rev Respir Dis 1987; 136: 416-9.

12 Heldr GP. Simultaneous quantification of chest wall distortion by multiple methods in preterm infants. Am Rev Respir Dis 1988; 138: 20-5.

13 Allen J, McDowel K, Wolfson M, Motley $R$, Shaffer $T$. Thoraco-abdominal asynchrony in infants with airflow obstruction. Am Rev Resp Dis 1988; 137: 379.

14 Agostoni E, Mognoni P. Deformation of the chest wall during breathing efforts. J Appl Physiol 1966; 21 : 1827-32. 